\title{
Determinação da qualidade da água através da aplicação da modelagem matemática em curso hídrico
}

\author{
Amanda de Cassia da Cunha ${ }^{1}$ \\ Mestrado em Tecnologia, FT, UNICAMP \\ 13484-332, Limeira, SP \\ ${ }^{1}$ E-mail: amanda_cunha1@yahoo.com.br / amanda.cunha@pos.ft.unicamp.br
}

\author{
Elaine Cristina Catapani Poletti ${ }^{2}$ Cassiana Maria Reganhan Coneglian ${ }^{3}$ \\ Aline Ortolani Sebuske ${ }^{1^{*}} \quad$ Sue Ellen Vanessa Pinheiro ${ }^{1^{*}}$ \\ Faculdade de Tecnologia, FT, UNICAMP \\ 13484-332, Limeira, SP \\ ${ }^{2}$ E-mail: elainec@ft.unicamp.br \\ ${ }^{3}$ E-mail: cassianac@ft.unicamp.br
}

\section{RESUMO}

A poluição hídrica, comumente observada no estado de São Paulo, devido ao lançamento de efluentes industriais e domésticos, assim como consequência da agricultura, compromete a qualidade da água para diversas finalidades, principalmente para o abastecimento público. A matéria orgânica gerada pela contaminação antrópica é um dos fatores responsáveis pela alteração na qualidade dos corpos aquáticos, por aumentar a disponibilidade de nutrientes como carbono e nitrogênio na água, proporcionando assim condições de crescimento da fauna hídrica e desequilíbrio no ambiente [7], [8].

Neste estudo, dois métodos indicadores são relevantes na quantificação de matéria orgânica. A Demanda Bioquímica de Oxigênio (DBO), que é a variável que quantifica o oxigênio consumido na degradação deste material orgânico [5], [1], e o Oxigênio Dissolvido (OD), variável que determina a quantidade de oxigênio presente na água, de forma dissolvida.

O oxigênio dissolvido é consumido pelas espécies presentes em ambiente aquático, incluindo bactérias degradadoras de matéria orgânica, e sua concentração pode determinar a presença de organismos e níveis de poluentes na água [3].

Associar o fator oxigênio consumido em processo de degradação com o oxigênio ainda presente na água, na forma dissolvida, permite o entendimento das condições de qualidade da água em análise, e a modelagem matemática corrobora um estudo preciso, tornando possível a compreensão do comportamento atual do oxigênio neste ambiente, e a simulação de quantidades adversas do gás dissolvido, a fim de se proporcionar uma reflexão à respeito da saúde do corpo hídrico.

Desta forma, utilizando-se parâmetros obtidos através de análises de DBO e OD do ribeirão Tatu, localizado na cidade de Limeira-SP, propõe-se uma modelagem com base num sistema de equações de diferenças, dado por [6], [2], [4]:

$$
C^{t+1}=C^{t}-\frac{F}{V} C^{t}-d C^{t}+q
$$

onde:

$$
\begin{aligned}
& C^{t+1} \quad \text { representa a DBO e OD no tempo } t+1 \mathrm{em} \mathrm{kg} / \mathrm{m}^{3} \text {; } \\
& C^{t} \quad \text { representa a DBO e OD no tempo } t \mathrm{em} \mathrm{kg} / \mathrm{m}^{3} \text {; } \\
& F \quad\left(\mathrm{~m}^{3} / \text { dia) e } V\left(\mathrm{~m}^{3}\right)\right. \text { representam o fluxo e o volume, respectivamente, da represa } \\
& d \quad\left(\mathrm{dia}^{-1}\right) \text { representa o potencial de degradação e } \\
& q \quad\left(\mathrm{~kg} / \mathrm{m}^{3} / \mathrm{dia}\right) \text { indica } \mathrm{o} \text { ingresso de carga orgânica poluidora. }
\end{aligned}
$$

As análises que alimentam o sistema foram realizadas no Laboratório de Análises Físico Químicas da Faculdade de Tecnologia. O referido ribeirão cobre, aproximadamente, $75 \%$ da área urbana da cidade de Limeira, possui cerca de $6,5 \mathrm{Km}$ de extensão e 14 afluentes. É de

\footnotetext{
* Bolsistas de Iniciação Científica pelo Programa SAE-UNICAMP.
} 
extrema relevância, pois passa pela região central da cidade: nasce na zona rural de Cordeirópolis e desagua no rio Piracicaba [9].

Este manancial possui inúmeros problemas, como falta de tratamento de esgoto, poluição urbana e industrial, além de ausência quase total de matas ciliares, que favorece diversos problemas de assoreamento e consequentemente a diminuição da capacidade de armazenamento de água e as enchentes na cidade, e a aplicação deste modelo matemático pode contribuir com o estudo dos agravos nele ocorridos.

Palavras-chave: Modelagem Matemática, Modelo discreto, Matéria Orgânica, DBO, OD

\section{Referências}

[1] BeRTOLETTI, E. e ZAGATTO, P. A., Ecotoxicologia Aquática: Princípios e aplicações, Capitulo 01, Ecotoxicologia, Ed.2, São Carlos - SP, Rimas, p.01, 2008.

[2] CARNIATO, N. K. S., Comportamento evolutivo de uma pluma superficial de poluente na bacia hidrográfica do Rio Mogi Guaçu, Dissertação de Mestrado, FEEC-UNICAMP, Campinas -SP, 2010.

[3] COMPANHIA AMBIENTAL DO ESTADO DE SÃO PAULO- CETESB (2013). Relatório de variáveis de qualidade das águas superficiais do Estado de São Paulo 2012. URL: <http://www.cetesb.sp.gov.br/mortandade/causas_oxigenio.php> acesso em 25 fev. 2014.

[4] JACOMINO, T. M. Z., Equações de Diferenças e Modelos Compartimentais no estudo, na Modelagem e em Simulações: Variação Temporal da Concentração de Poluentes na Lagoa de Cima em Campos dos Goytacazes - RJ, 2006.

[5] Mano B. E., Pacheco V. A. B. E., Bonelli C. M. C., MEIO AMBIENTE, POLUIÇÃO E RECICLAGEM. $2^{\circ}$ Edição, Editora Edgard Blucher Ltda., Pag 41, 2010.

[6] MONTOVANI, C. P., O impacto ambiental na bacia do Ribeirão do Pinhal - município de Limeira-SP: Caracterização, modelagem matemática e discussões Limeira, Dissertação de Mestrado, FT-UNICAMP, Limeira-SP, 2012.

[7] MONTOVANI, C. P. e POLETTI, E. C. C., O impacto ambiental na bacia do Ribeirão do Pinhal - município de Limeira-SP: Caracterização, modelagem matemática e discussões, Biomatemática, 22, p 105 - 116, 2012.

[8] OPPA, L. F., Utilização de Modelo Matemático de Qualidade da Água Para Análise de Alternativas de Enquadramento do Rio Vacaraí Mirim, Dissertação de Mestrado, UFSM, Santa Maria - RS, 2007.

[9] REGATTIERI, S. M. C. B., Geoquímica de águas e sedimentos da bacia do ribeirão Tatu, Limeira-SP, Dissertação de Mestrado, Instituto de Geociências, UNICAMP, Campinas-SP, 2007.

\footnotetext{
* Bolsistas de Iniciação Científica pelo Programa SAE-UNICAMP.
} 